\title{
Marcas da Ooó *
}

\section{João Batista Santiago Sobrinho**}

Rosa é um criador delirante, suponho, exatamente porque possui o sentimento da infância.

Heriqueta Lisboa.

O O é um buraco não esburacado.

Joäo Guimaräes Rosa

Resumo: Neste estudo pretendemos perscrutar, entre a escritura e o escritor, um aspecto da estética rosiana capaz de sintetizar, em alguns momentos, nas conexões das letras, como um ideograma, o caráter polifônico do texto.

Nos bastidores rosianos encontramos um homem afável cujo gênio é disposto, tanto ao sertão mais erudito, filosófico, como às crianças. Como Heráclito, Guimarães Rosa sabia que lidar com crianças é "cuidar do extraordinário" (HEIDEGER, 1998:27).

Uma história que sei, e conto, mais ou menos verdadeira, passa-se na casa de Gilda Marcondes, minha querida amiga que Rosa apelidou carinhosamente de "Pelinha" - (Este apelido

\footnotetext{
- Recebido para publicação em novembro de 2004.

• Doutorando da Pós-Lit - Programa de Pós-Graduação em Letras: Estudos Literários, Faculdade de Letras/UFMG.
} 
carinhoso "Pelinha" encontra-se registrado na primeira edição que o autor autografou e deu a Gilda Marcondes como prova de amizade).

Na cidade do Rio de Janeiro, chamando-se ali, o palquinho onde a história acontece, casa da rua Sambaíba. Com um espírito fanfarrão e um indefectível guarda-chuva, que Rosa não abandonava nunca, pois tinha utilidades inimagináveis, e só por este pequeno evento que narrarei, valeria carregá-lo, mesmo não havendo sol, nem chuva nunca mais. Vinha chegando Rosa à casa da rua Sambaíba e lá os meninos aflitos preparavam-se para o ritual. Sucesso de quase todos os dias em que Rosa vinha visitar a família Marcondes. Em frente da casa, "metros da linha da rua formava-se ali uma espécie" de labirinto, um zig-zag, um $z$ de escadas para evitar o lance bruto até a casa que recendia meio ao céu. Lá dentro os meninos salivavam, enchiam boquinhas. Cá fora Rosa acudia a brincadeira sorrindo, mas sério, quando já quase chegando à porta da casa, no último lance da escada, abria o guarda-chuva de repente, para receber a chuvinha de culpes da meninada, os filhos de Chiquita Marcondes. Este espírito rosiano é facilmente comprovável no livro Correspondência de João Guimarães Rosa, vovô Joãozinbo, com Vera e Beatriz Helena Tess, em que ele se derrama de amores escriturais por suas netas emprestadas, mas verdadeiras. Vera que receberá o apelido de Ooó e Beatriz Helena Tess eram netas de Aracy, esposa do segundo casamento de Guimarães Rosa, do qual não tiveram filhos.

Uma referência importante desse intercâmbio, produto do imaginário lúdico, ingênuo, do vovô Guimarães Rosa, é a presença da netinha Ooó, que se transforma em personagem do livro Tutaméia, considerado pelos críticos, espécie de chaveenigma para compreender o universo rosiano. No conto "Mechéu", ooó é "a menina, neném, ooó, menina de inéditos gestos" 
(ROSA, 1967:89). O vocabulário dessa menina se assemelha a de outros personagens rosianos, como Nhinhinha, "A menina de lá" do livro Primeira estórias que de tão encantada transcende. A expressão "neném e meninas" (ROSA, 2003:50), o avô Guimarães Rosa utiliza em vários momentos de suas cartas para as netinhas. Mas com a "ooó" no conto "Mechéu", vida, obra e arte misturamse definitivamente. Guimarães Rosa parafraseia o discurso da neta, quando inventa que a personagem "ooó", que diz ao "semi-imbecil" Mechéu - que faz par com um "bobo, bem, meio idiota papudo era outro, o que de alcunha o Gango" (ROSA, 1967: 89) - "você é bobo não, você é bom" ou canta "- Michéu, bambéu... Michéu... bambéu... -"(ROSA, 1967: 89). Guimarães Rosa não fazia distinção entre vida e obra, segundo ele, na entrevista concedida a Gunter Lorenz "a vida deve fazer justiça à obra e a obra à vida" (ROSA, 1991: 74).

Mas também é possível vê-lo, o espírito ingênuo do vovô Rosa, nos inúmeros diminutivos que recendem na obra rosiana, como por exemplo, o "riachinho", personagem metonímico na perspectiva hídrica das análises das imagens de água ${ }^{1}$. Para Bachelard, "no riacho quem fala é a natureza criança" (BACHELARD, 1998:35). Rosa percebe esta natureza e cria o neologismo "Bilbo" - último suspiro do riachinho - "a derradeira gota, o bilbo", (ROSA, 1956:90), para referir-se à morte do riachinho no conto Manuelzão, uma estória de amor". Bachelard afirma que

é difícil para os poetas desprender-se dessa poesia infantil. Entre numerosos poetas, os regatos dizem os seus glu-glu com esse mesmo tom nos dissílabos das pobres consoantes: dada, bobô, lolô, cocô. Assim cantam

\footnotetext{
' Imagens da água no romance Grande sertão: veredas de Joāo Guimarães Rosa, defendida por mim em 2003 na faculdade de Letras da UFMG.
} 
os riachos nos contos infantis inventados pelos adultos. (BACHELARD, 1998:35).

Os diminutivos rosianos não aparecerão na tradução alemã, porque segundo seu tradutor alemão Curt Meyer-Clason, a língua alemã é arredia aos diminutivos. "Não esqueça [referindose a Guimarães Rosa] que minha língua se nega a conceber coisas com 'dormidinho, vestidinha' etc." (ROSA, 2003: 301). Questão naturalmente superada, dado sucesso da tradução de Clason.

Oliveira, em sua dissertação O discurso lúdico de Guimarães Rosa em Sagarana, desenvolve toda uma pesquisa que passa pelo jogo, a ingenuidade, a caricatura e o humor. A certa altura referindo-se à capacidade imagética da escritura rosiana ele afirma:

Nas miniaturas rosianas não há apenas uma diferença de tamanho. Cada parte do objeto descrito deve ser imaginada como um brinquedo do narrador. Imaginar determinada situação ou objeto com brinquedo é criar uma representação autônoma, onde a fantasia se amplia através de um movimento de condensação do próprio objeto, fazendo com que a realidade descrita seja representada, desenhada como enfeite pelo puro prazer lúdico. (OLIVEIRA, 1981:50).

O que nos chama a atenção é que na descrição de Oliveira, além do aspecto lúdico ressaltado no espírito da escritura rosiana, que perpassa toda a obra do escritor, é a presença da palavra "desenhada", em meio à sua análise. Há na escritura rosiana um desejo de materializar-se em desenho. Guimarães Rosa era um desenhista delicado como podemos notar a propósito de suas correspondência com as netinhas, de suas cartas aos tradutores, principalmente àquelas escritas à tradutora norte-americana, 
em que ele vê a necessidade de desenhar, sementinhas, carros de bois, para dar idéia exata à tradutora da realidade que ele captara detalhadamente do sertão. E esta relação lúdica com o desenho termina por transparecer nas capas e orelhas de seus livros. "O ARRAIAL DE BARRA-DO-VACA, NAS CERCANIAS DE PARACATU, a que alude Afonso Arinos, está indicado neste desenho pitoresco que Poty fez - a pedido e sob a orientação de Rosa para a $2^{\text {a }}$ edição de Grande Sertão." (ROSA, 1968:104). Desde Sagarana, a relação do autor com o desenho é de intenso diálogo. Em, Primeiras estórias e Tutaméia, os desenhos de Luiz Jardim buscam reproduzir o aspecto lúdico, infantil, que encontramos nos desenhos que Guimarães Rosa fez para Vera e Beatriz Tess. É justamente o encontro na conjunção mais delicada letra: desenho, ícone, que pretendemos aplicar nossa lupa. O traço do desenhista Guimarães Rosa dialoga com desenho de Luiz Jardim, conforme podemos perceber comparando os desenhos de ambos:

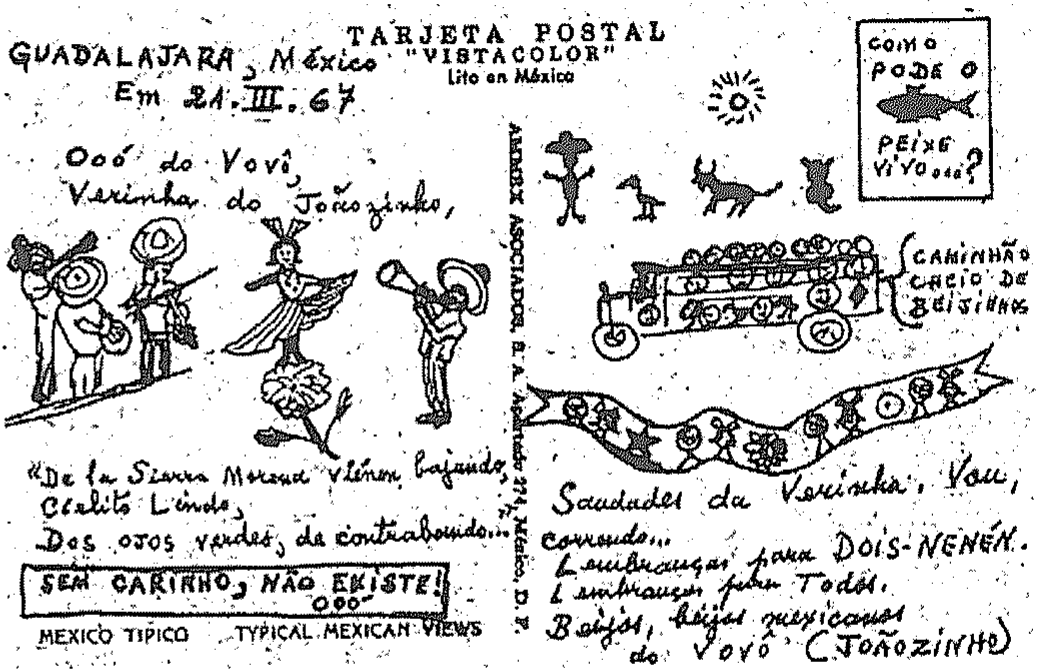




\section{JOAिO CUIMARÄES ROSA}

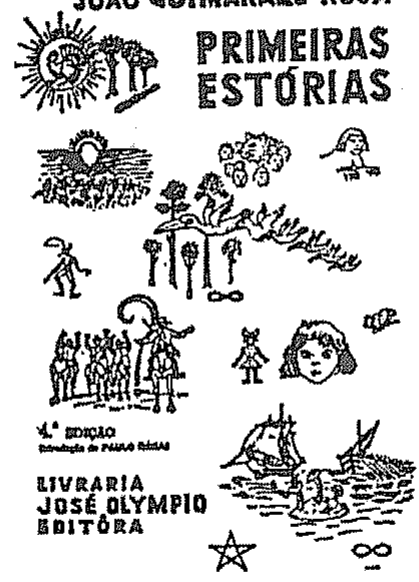

No livro Tutaméia, a forma arredondada do traço de Luiz Jardim pode ser confrontada com um outro postal, este enviado para Verinha, em que os traços de ambos produzem um desenho mais agudo. Lembramos que as cartas para as "netas" foram escritas no período que vai de 1966 a 1967. Período em que Guimarães Rosa organizava o livro Tutaméia. Vejam a semelhança entre os porquinhos rosianos e os animais e homens desenhados por Luiz Jardim:

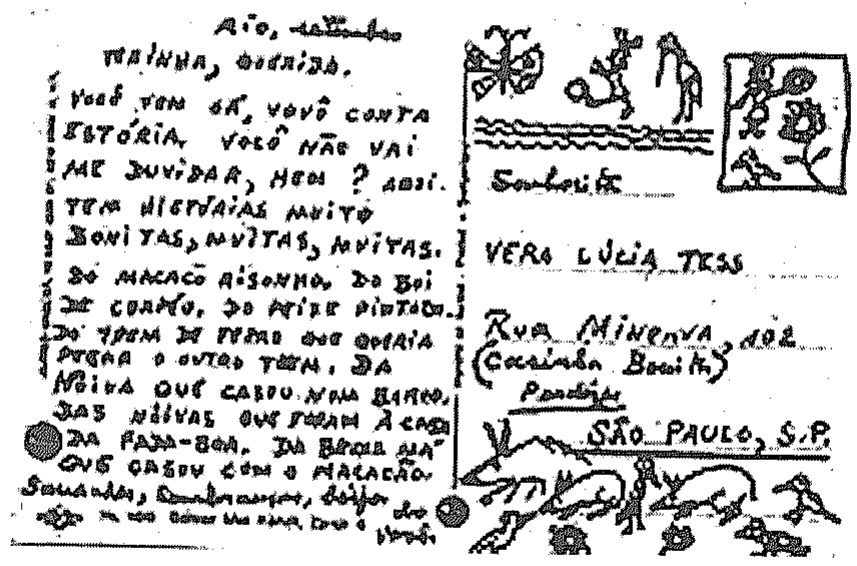




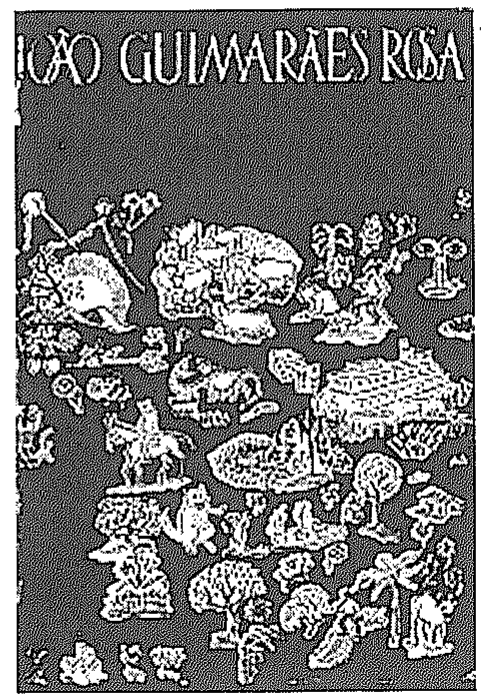

Não é ao acaso que esta escritura irá inspirar artistas com Arlindo Daibert, que em variada técnica irá dispor no livro Imagens do Grande Sertão uma verdadeira cosmogonia simbólica, presentes na obra rosiana. Outra autora que se deterá sobre este aspecto imagético é Walnice Nogueira Galvão, quando analisa no conto de Sagarana "A hora e a vez de Augusto Matraga" a marca - um triangulo - que os inimigos deste lhe fizera no corpo. O texto de Walnice, como as gravuras de Arlindo Daibert, transitam entre o local e universal e corroboram a vocação emblemática do texto rosiano.

De agora em diante buscaremos o traço do desenhista Guimarães Rosa na letra. Foi a letra que de fato inspirou-nos a realização do estudo. Encontramos no conto "O recado do Morro" logo de início, um "S" que representa a estrada e a própria sinuosidade da narrativa rosiana: "Desde ali, o ocre da estrada, como de costume, é um S, que começa grande frase". (ROSA, 1956:239). Lembrando que a grande frase "o próprio conto" 
começa com um $S$ que na primeira edição se destaca: "Sem que se saiba conseguiu-se rastrear pelo avesso um caso de vida e morte..." (ROSA, 1956:239). Neste mesmo conto, Sandra Guardini Teixeira Vasconcelos em texto intitulado "Guardados da memória: as cadernetas de campo de Guimarães Rosa", chama a atenção para a semelhança entre "seo Olquiste" e Guimarães Rosa que
anotava e desenhava tudo o que via.

Durante a expedição de naturalistas que atravessa o sertão, em O Recado do Morro, seo Olquiste, de "codaque" e de binóculo, inventaria o perfil geográfico e geológico da região, com suas lagoas, lapas, cavernas; grutas e morros. A cavalo, tomando notas em sua caderneta, faz perguntas e desenha ("de tudo tirava traço e figura leal"). Nada the escapa: nem os detalhes da fauna e da flora, nem as conversas e casos, nem as minúcias do cotidiano de seus acompanhantes. Esse forasteiro de óculos e fala enrolada em tudo lembra a figura de seu criador. Tal qual seu personagem, Guimarães Rosa também fez sua travessia do sertão, em maio de 1952, tangendo boi com a comitiva de Manoel Nardy pelo interior de Minas Gerais, como ilustram as fotos da reportagem publicada pela revista $O$ Cruzeiro em junho do mesmo ano. Se em Olquiste, entretanto, transfigurase o cientista, preocupado em observar e registrar suas descobertas sobre a paisagem natural, Guimarães Rosa revela, no seu reencontro com sua terra natal, sua face de etnógrafo, interessado não apenas na cartografia da região, mas sobretudo na cultura dos boiadeiros $\mathrm{e}$ sertanejos que povoaram sua obra. (http://www.
Klickescritores.com.br/pag_imortais/rosa_fot6.htm) 
Kathrim Rosenfield, com notável percepção das misturas estilísticas rosianas, pergunta se a alegria rosiana é um princípio filosófico ou estético. O que tratamos aqui é do gênio desenhista, ingênuo, dos estados brutos da alegria, que se entremeia a paixão medida do escritor, sua escritura, como "pequeninos nadas" - expressão de Manuel Bandeira - as "Marcas da Ooó". Uma alegria portanto arrecadada na vida e transplantada para a escritura. Tratamos do "João [que] propondo desenhos figurava menos a resposta que outra questão ao perguntante ? $^{2}$

$\mathrm{Na}$ obra rosiana o infantil se distingue como anteparo ao sério. A alegria no imaginário rosiano é espécie de norte escritural. Não teríamos como desgangarizá-la, senão por intermédio de apontamentos, fissuras neurais da grande rede escritural sobre a qual a alegria amalgama-se. Como o fazem as veredas no sertão, a alegria está em toda parte. Segundo Bachelard, "em vista dessa necessidade de seduzir, a imaginação trabalha mais geralmente onde vai a alegria - ou pelo menos onde vai uma alegria! - no sentido das formas e das cores, no sentido das variedades e das metamorfoses, no sentido de um porvir da superfície." (BACHELARD, 1998:02).

Henriqueta Lisboa afirma que Miguilim, "o menino de 'Campo Geral' reponta com surpreendente vitalidade em tudo quanto escreve o nosso autor" (LISBOA, 1991:171), como uma espécie de "eu profundo" bergsoniano - ela diz - a natureza instintiva e emotiva de Rosa manifesta-se em toda sua escritura. O surpreendente é que a vemos manifestar-se na forma, a escrita como um ícone, um desenho da idéia. Não imaginam vocês a alegria dos alunos ao descobrirem, sob a indução do professor leitor, estas pequenas marcas no texto.

\footnotetext{
${ }^{2}$ Poema de Carlos Drummond de Andrade "Um chamado João" que se encontra na introdução do livro Primeiras estórias e do livro em memória a João Guimarães Rosa.
} 
Tentando corroborar a linearidade precária da língua, a forma, a letra, personifica-se, como no conto "Famigerado", ou animaliza-se como no conto "Meu tio Iauaretê". A prosopopéia é recorrente na obra rosiana e merece estudo à parte. Naquele conto, estória para "alto rir", expressão do narrador, um médico de uma cidadezinha qualquer, terá de resolver um problema "hermenêutico" de alta periculosidade, ou seja, explicar ao ferocíssimo assassino Damásio, responsável por dezenas de mortes que o adjetivo famigerado é, na verdade, um elogio, embora a palavra também contenha conotações pejorativas, como mal-afamado e esfomeado. Acepções que o narrador vai evitar para não despertar a ira de Damásio, desconfiadíssimo do teor ruim da palavra que lhe fora dita por um certo fiscal do governo. Mas que não quer cometer uma injustiça, por isso saíra pelo sertão buscando alguém instruído e confiável para explicar-lhe o significado verdadeiro da palavia. Temendo ser morto a cada momento passado ao lado do Jagunço e suas três testemunhas que também poderiam morrer, o narrador diz a certa altura, aquilo que estamos chamando de "Marcas da Ooó": "O medo O. O medo me miava." (grifo nosso) (ROSA, 1962:09). Percebemos que não se termina uma frase com letra maiúscula, senão com intenções estéticas. Cremos que Rosa utiliza o formato das letras para reproduzir o medo, tanto em seu aspecto sonoro, quanto em seu aspecto visual, na medida que pretende expressar o olhos arregalados de alguém que está amedrontado, nesse caso o próprio narrador, que se confunde na figura do próprio autor, pois trata-se de um médico do interior. Ainda neste conto, a Serra do São Ão, o "A" maiúsculo e "o" minúsculo reproduzem o esquema de uma serra, se traçarmos um risco em volta das letras teremos o desenho perfeito de uma montanha. E se mais imaginarmos o "til" pode ser um passarinho. 
No conto "Meu tio Iauaretê" percebemos as "Marcas da Ooó" como marca das patas da onça se repetindo pelo conto na expressão "Ói:" (grifo nosso) ${ }^{3}$ que aparece no conto, pela primeira vez, no momento em que o narrador, o próprio Iauaretê, está contando sobre a onça Maria-Maria, que ele não mata, pois gosta dela e a descreve com intimidades e ciúmes. "Ela tem macho não. Xô! Pa! Atimbora! Se algum macho vier, eu mato, mato, mato, pode ser meu parente o que for." (ROSA, 1976:139).

Mesmo esse aspecto repetitivo da expressão Ói: é representativo do universo infantil que corrobora na letra, uma unidade de sentido, que estamos chamando de "marcas da Ooó". No meio do conto, aparece a primeira marca que representa a transformação do narrador em onça: "A'bom, mas agora mecê carece de dormir. Eu também. Ói: muito tarde." (ROSA, 1976:140). A última frase soa ambiguamente, como um aviso da morte eminente do narratário e de transformação do narrador em onça. Logo a frente outra marca, "Hã, a'bom. Ói: em covoca da banda dali, aqui mesmo pertinho, tem a onça Mopoca, cangussu fêmeo." (ROSA, 1976:140). Aqui fazemos uma exposição do aparecimento dessas marcas na seqüência em que elas aparecem no conto: "Oi: mais adiante, no rumo mesmo, obra de cinco léguas, tá a onça pior de todas, a Maramonhangara, ela manda, briga com as outras, entesta." (ROSA, 1976:141). "Ói: onça Maria-Maria eu vou trazer para cá, deixo macho nenhum com ela não." (ROSA, 1976:142). "Ói:, me dá sua mão... Dá sua mão, deixa eu pegar... Só um tiquinho." (ROSA, 1976, p. 140). "Ói: eu tava lá, matei nunca ninguém" ( ROSA, 1976:148). "'Ói: sua mãe deve de ter sido bonita, boazinha muito boa, será?'" (ROSA, 1976:157), "Ói: deixa eu ver mecê direito, deix'eu pegar um tiquinho em mecê, tiquinho só encostar minha mão..." (ROSA,

\footnotetext{
${ }^{3}$ a expressão Oi: doravante aparecerá grifada em nosso texto..
} 
1976:158). E finalmente aquela marca mais comprobatória de nosso olhar referente às "marcas da ooó" em Meu tio Iauaretê, a qual é espécie de síntese da transformação do caçador de onças em onça, que a partir do desenho da letra, na verdade está "literalmente" pondo a pata no chão: "Ói: tou pondo a mão no chão é por nada não é à-toa.." (ROSA, 1976:158).

Nấo thes parece a própria onça salpicando suas patas? Cremos que sim.

Assim, aplicamo-nos em buscar na crítica, nos narradores rosianos e no próprio autor aspectos da alegria ingênua que contribui sobremaneira para sua "delirante" escritura, que ao procurar reinventar a língua, aplica-se também em potencializála na letra iconizada, como metonímia da escritura. Há um procedimento rosiano que se repete em toda sua obra, aquele em que o pequeno contém o grande e o grande contém o pequeno. Neste nosso estudo a letra, como desenho, apresenta-se como síntese da escritura de João Guimarães Rosa.

Résumé: Cette étude vise identifier, entre lécriture et lécrivain, un aspect de l'esthétique de Guimarães Rosa capable de synthétiser, comme un idéogramme, dans les connexions des lettres, le caractère polyphonique du texte.

\section{Referências Bibliográficas} BACHELARD, Gaston. A água e os sonhos. São Paulo: Martins Fontes,
1998.

OLIVEIRA, Edson Santos de. O discurso húdico de Guimarães Rosa em Sagarana. Belo Horizonte/UFMG, 1981. (dissertação de Mestrado). 
HEIDEGGER, Martim. Heráclito. Rio de Janeiro: Relume Dumará, 1998.

ROSA, João Guimarães. Fortuna crítica. Rio de Janeiro: Civilização Brasileira, 1991.

ROSA, João Guimarães. Meu tio ianaretê. Rio de Janeiro: José Olympio, 1976.

ROSA, Joāo Guimarães. Tutaméia. Rio de Janeiro: José Olympio, 1967.

ROSA, João Guimarães. Primeiras estórias. Rio de Janeiro: José Olympio, 1962.

ROSA, João Guimarães. Correspondência de João Guimaräes Rosa, vovô Joãozinho, com Vera e Beatriz Helena Tess. São Paulo: Edusp, 2003.

SANTIAGO SOBRINHO. As imagens de água no romance Grande sertão:veredas de João Guimarães Rosa. Belo Horizonte/UFMG, 2003. (dissertação de Mestrado).

http://www.klickescritores.com.br/pag_imortais/rosa_fort6.htm 